\title{
Research on the Application of Computer in Enterprise Economic Man- agement
}

\author{
Zengwu $\mathrm{Li}^{*}$ and Xiong Xiong
}

Southwest Jiaotong University-Emei, Sichuan, China, 614202

\begin{abstract}
As is known to all, the power that enterprise development never dried up is innovation, and the beacon that the enterprise is eternal pursuit is economic interest, Among them, the key to the development of the enterprise is the economic management of the enterprise. In order to get better economic benefits and social benefits, enterprises must rely on advanced economic management. So how to strengthen and innovate enterprise economic management, has been a high degree of concern for the business management community. Under the new situation of the rapid development of computer technology, to do a good job of enterprise economic management, maximize reduce cost of enterprise material management, it is necessary to realize the application of computer technology in enterprise's economic management. The perfect enterprise information platform means the construction of server and workstation with more powerful function. In order to integrate the requirements of the enterprise, such as frequent operation, graphics processing, operation perfect and large-scale database integration and so on.
\end{abstract}

Keywords: Computer, economic interests, economic management, enterprise.

\section{INTRODUCTION}

The overall symbol of the enterprise's comprehensive strength is the benign development of the enterprise economy, which is particularly evident in our country's continuous development market economy. The modern enterprise has clear responsibilities, clear property rights, separation of enterprise from administration of independent legal entities and market entity, the core of enterprise management is modern enterprise economic management issues in the practice of the modern enterprise system in China which has been proved. In the rapid development of the market economy, the pursuit of the enterprise is to continuously improve the competitiveness of the enterprise market, so as to continuously improve profitability. If the enterprise wants to be in an invincible position, it should do well to reduce the cost and raise the income of two aspects, both hands hard. And the development and application of computer has already become people learn new knowledge and master new skills that is an important way, in enterprise management in the use of computer technology to effectively reduce the cost of enterprise and continuously improve the production efficiency, but also can reduce the input of human resources, so companies need as soon as possible to establish and perfect the system of information management.

\section{ECONOMIC MANAGEMENT}

\subsection{The Meaning of Economic Management}

Economic management [1] refers to the enterprise operation and management to achieve the intended target, the enterprise production and business activities or social and economic activities and the implementation of the planning, organization, command, coordination and supervision activities. In brief, the economic management is the enterprise management to the enterprise economic activity carries on the management activity.

\subsection{The Significance of Economic Management}

Enterprise management activities are based on the economic management of enterprises. Enterprise economic management should continue to reform and innovation activities to guide the practice of the enterprise, and only in this way can realize the effective management of the enterprise. Effective business management can not only clear enterprise's future development direction, but also be able to promote the implementation of the rules and regulations of the enterprise, promote employees to play their own potential, and bring more economic value and intangible value for the enterprise. In the process of the development of enterprises and daily work and economic management of enterprises and enterprises to strengthen market competitiveness play to important guiding significance [2], not only to promote the economic profit of enterprises long-term, stable and sustained growth, to maintain the enterprise's daily operation.

\subsection{Enterprise Economic Management System}

The enterprise top management should be to the enterprise staff publicity the importance of economic laws, regulations and enterprise economic rules and regulations, formulation of economic policy and economic objectives, to ensure that the resources needed for the economic management of and economic management system planning and on economic management system planning changes and the implementation, should maintain the integrity of the system of 


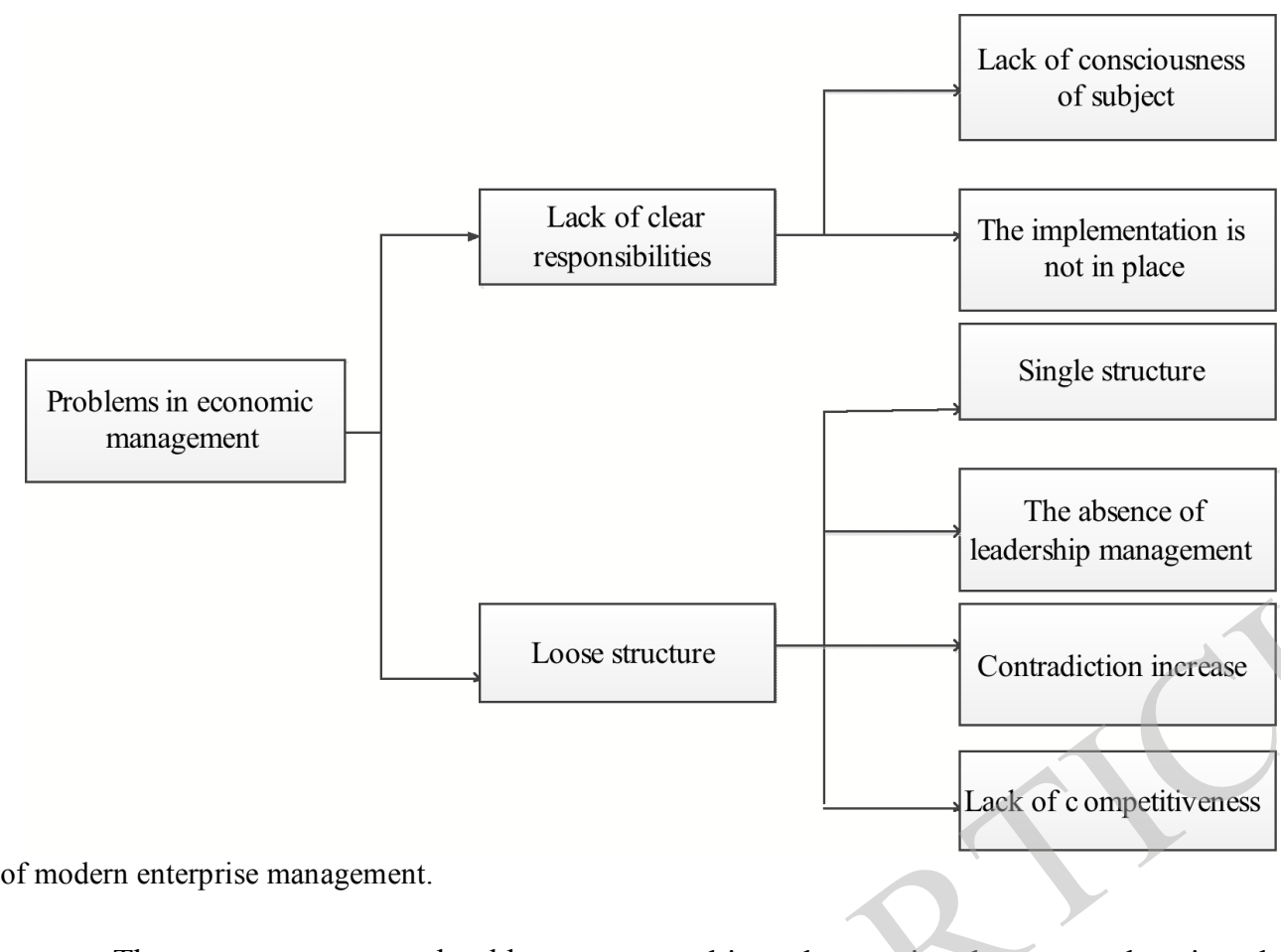

Fig. (1). Analysis of modern enterprise management

economic management. The top management should ensure that the economic management policy is compatible with the purpose of the enterprise, including the effectiveness of the economic management requirements and the continuous improvement of the economic management system. The top management of the enterprise should enhance the customer and the related party's satisfaction as the purpose, and ensure the customer and the related party's request to obtain confirmation and satisfy [3]. The top management of the enterprise shall ensure that the responsibilities and authorities of the economic manager within the enterprise shall be stipulated and confirmed. The establishment of communication process in the enterprise within and ensure the effectiveness of the economic management system of communication.

Enterprise top management should be designated representatives of economic management system, and grant certain duties and authority, to ensure that the processes needed for the economic management system are established, implemented and maintained [4], to top management reporting economic management system of performance and improved demand, to ensure the promotion of awareness of meeting requirements of customers and stakeholders and the enterprise regulation within the organization as a whole.

\section{PROBLEMS OF ECONOMIC MANAGEMENT IN MODERN ENTERPRISE}

The problems that existed in the economic management of modern enterprise include the following two aspects (See Fig. 1).

\subsection{Enterprise Management Lack of Clear Respon- sibilities}

The enterprise management without main body consciousness will fall into the vicious circle which is not clear in responsibility [5]. It will affect the establishment of the economic management system of the modern enterprise, and ultimately restrict the comprehensive development of the enterprise. Enterprise business activities of the main goal is the maximization of economic benefits, modern enterprise economic management is to maintain a strong guarantee for the direction of, in the growing socialist market economy today, the enterprise has been given more development tasks and goals, in addition to focus on economic benefits of this basic pointed out, modern enterprise should also have a system thought and consciousness of overall situation, should pay attention to the comprehensive development of enterprises environmental benefits [6], social benefits and other benefits, otherwise enterprises will lost his balance and development process of the block and the development direction of the lost. The enterprise leaders and managers by traditional economic and business management concept, ignoring the work of enterprises of systematic and comprehensive, lead to the existence of the problem on the communication and exchange gap between the enterprise among the various departments and the staff, especially the identification of management responsibilities and division of responsibility, often because of the lack of management consciousness and lead to the responsibility is not clear. Some enterprises have failed to implement the essence of modern enterprise economic management in place, management measures and the system as furnishings, such economic management is not conducive to stimulate the enthusiasm of the employees, and not conducive to enterprise management function and efficiency of the play, is not conducive to enterprise's long-term development become the obstacle of enterprise growth, difficult to really play the advantages and strengths of the management of modern enterprises.

\subsection{Enterprise Management Organization Structure is Loose}

The current enterprise management structure of the organization is loose mainly has following several aspects: first, the organization structure of enterprise management will be 
influenced by the traditional management thought and the thinking tendency [7]. A lot of enterprises adopt the operation and management of the line, although the management function can be completed relatively, but the easy form adult floating in the matter and the overlap of the organization. Second, the corporate management structure of the organization is loose will cause the lack of leadership, no rigorous structure leadership will not timely comprehensive master of enterprise's economic situation, the leadership appears to disregard for economic management, which for the economics and management of modern enterprises is undoubtedly a very negative impact [8]. Third, the modern enterprise system, departments and individuals see there is a great blend, each other with essential, various contradictions are inevitable, if pine corporate management organization, will result in increased conflict and combination of lower, which is not conducive to enterprise own value, their own interests, for their own development. Fourth, the enterprise management structure of the organization is loose will reduce enterprises that are in the face of market competitiveness, performance for enterprise's ability to adapt to reduce, not only can improve enterprise efficiency, and can't timely adjustment direction of enterprise development, also cannot accelerate enterprises to adapt to market needs, in short, a serious impact on economic and business management [9], hinder the enterprises to achieve sustainable development and continuous progress.

\section{SIGNIFICANCE OF COMPUTER APPLICATION IN ENTERPRISE ECONOMIC MANAGEMENT}

With the arrival of the information age, the use of information has been utilized to all walks of life. Enterprise economic management is the first, the application of computer technology in enterprise economic management has been very extensive, and the role of enterprise economic management is increasingly demonstrated.

The application of computer technology in enterprise economic management is increasingly recognized and respected. Because in enterprise economic management, scientific use of computer technology, to encourage enterprises to achieve rapid from traditional management to information management mode change, prompted enterprise rapid response management, shorten operating time of the enterprise economic management staff to cope with the numerous work to achieve economic plan and scientific enterprise [10], scientific and effective to collect feedback information of enterprises in a variety of so that the data is more reliable.

The application of computer technology in enterprise's economic management has become the main means of the modern enterprise management, through the computer technology can further optimize business processes in the enterprise, convenient to the enterprise scientific and effective management and control, greatly enhance the enterprise's comprehensive competitiveness, the enterprise long-term stable development escorts the Emperor convoy.

Currently the application of computer in the business management is not enough, in some economically backward areas, enterprises in the management of computer applications is not deep enough, more just for recording and storage of the simple, is not able to use computer technology to carry out scientific analysis, using the advanced function of computer technology. In contrast, the eastern part of the economy developed more than the western economic underdeveloped areas should be more extensive.

In some areas of computer technology is still in the enterprise the old management system and management mode, which makes the advanced computer technology can get allround development, to a certain extent also hindered the application of computer science and technology.

\section{THE APPLICATION EFFECT OF COMPUTER TECHNOLOGY IN ENTERPRISE ECONOMIC MANAGEMENT}

\subsection{The Application of Computer Technology can Real- ize the Standardization of Business Management in En- terprise Economic Management}

With the application of computer technology, enterprises can be more scientific and effective basic data management, and effectively speed up the entire enterprise information flow speed. With the help of the application of computer technology, key enterprises in the process of economic management unit code, material coding, and so on a variety of basic data can be unified, on the basis of, by way of work flow to quickly transfer all aspects of enterprise goods and materials enter the order, submit, review, inbound, outbound, return information [11], thus maximize prevents the error problem caused by the traditional manual mode of operation, to ensure the effectiveness of enterprise material management, avoid material enterprises appear situation that is that account real do not conform. At the same time, the application of computer technology can more scientific and effective management of a variety of auxiliary materials in the enterprise. Enterprise material purchasing plan, prepared by a single, invoices, and storage of a single information entry is let the enterprise material planner to deal with that before being enterprise storage of materials, for enterprise material acceptance and confirmation of input and output are by special inspectors and warehouse keeper to carry on processing. Acceptance of the enterprise warehouse data storage can for the procurement of goods analysis of the creation of important data support, and for enterprise accounting payable [12], paid to create scientific and effective data support, and ultimately to maximize reach the organic connection of the enterprise inventory management, plan management, purchase management, ultimately promote the enterprise material management level greatly enhance.

\subsection{With the Help of the Application of Computer Tech- nology Which can Realize the Enterprise Financial Transparency Management}

With the help of the application of computer technology, enterprise is able to the organic unity of the science effective management enterprise logistics and capital flow, realizing the enterprise in the process of economic management of procurement, storage, a library, and so on a series of business links. At the same time, with in the application of computer technology, can ensure enterprise material information tracking, and also can ensure the effective sharing of information involved in the management of the enterprise economy financial, warehousing, logistics and so on different 


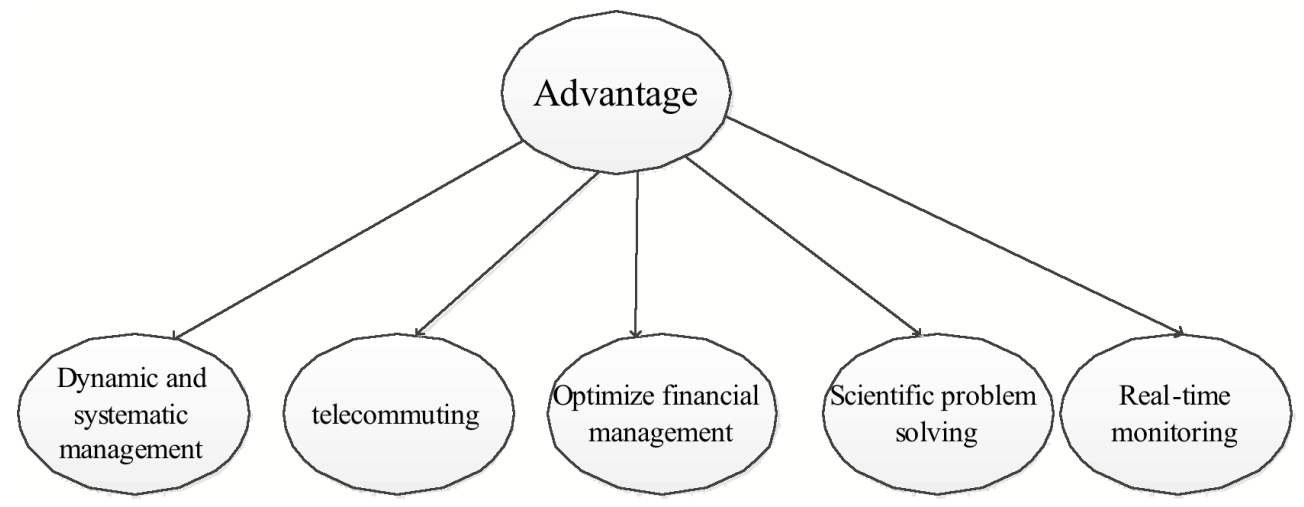

Fig. (2). The advantage of computer application in enterprise economic management.

offices. From this, with the help of computer technology, enterprises can more and more transparently to the financial management work.

\subsection{The Application of Computer Technology can Real- ize the Enterprise Economic Information Monitoring and Warning}

Application of computer technology can do the daily management of the enterprise economic and scientific effectively monitoring enterprise better in all materials procurement, storage and distribution, which can effectively found and solve the problems. With the help of in the application of computer technology, to maximize prevent inaccurate enterprise material requirements planning, procurement departments blind procurement problems, so as to prevent the emergence of enterprise material purchasing risk. In the process of real-time monitoring of the inventory, with in the application of computer technology, also to the various problems for advance warning. Only in this way can a scientific and effective coping overstored inventory alarm, obsolete inventory warning stock capital turnover is slow and blind procurement to enterprise economic management, achieved good results.

\section{THE ADVANTAGE OF COMPUTER TECHNOL- OGY IN ENTERPRISE ECONOMIC MANAGEMENT}

The advantage of computer technology in enterprise economic management is reflected in many aspects (See Fig. 2).

The application of computer technology in enterprise economic management can impel the enterprise economic situation to be dynamic and systematic management. Through the computer management system, it can ensure real-time monitoring and scientific management in the enterprise management to the company's business and project activities, through the use of computer network view research and analysis to the operation and management of enterprises, the timely development of relevant countermeasures and measures, in the doomsday of improve the efficiency of enterprise financial management, and utilize the funds of funds overall turnover.

Through computer management system, the enterprise administrator can develop the remote office under the mobile office condition. Through the application of computer technology, with a large amount of market data as the basis, analysis and processing, can facilitate the management improve management decision-making accuracy, scientific and modern, promote enterprises to grasp the market information.

Enterprises through the application of computer technology to science effectively management enterprise logistics and capital flow, realize the effective sharing of information involved in the management of the enterprise economy financial, warehousing, logistics and so on different offices, which can full control of enterprise materials information, more transparency in financial management.

The strengthening of computer technology application, can promote managers better do the daily management of the enterprise economy, and discover the problems appeared in management, scientific and effective to solve the problem, in the maximum to prevent inaccurate enterprise material requirements planning, procurement departments blind purchase [13], to prevent enterprises procurement risk.

Through the application of computer technology, can promote the enterprise in the process of real-time monitoring of the inventory timely on a variety of issues, early warning, so as to ensure that the managers in the shortest time scientific and effective coping overstored inventory alarm [14], obsolete inventory warning stock fund week turn slow and blind procurement problems and promote the enterprise economic management to achieve good effect.

\section{THE FUNCTION OF COMPUTER IN ENTERPRISE ECONOMIC MANAGEMENT}

The emergence of computer technology has provided a lot of convenience for the enterprise, also has played a great role in improving the financial management (See Fig. 3).

\subsection{Strengthen the Financial Management}

As the top priority of financial work, the application of computer in financial management has brought a lot of impact on the application of financial management.

\subsection{Strengthen Internal Control of Enterprise}

The work of enterprise financial management involves many different factors, so this work is also the coordination of multi departments to complete. 


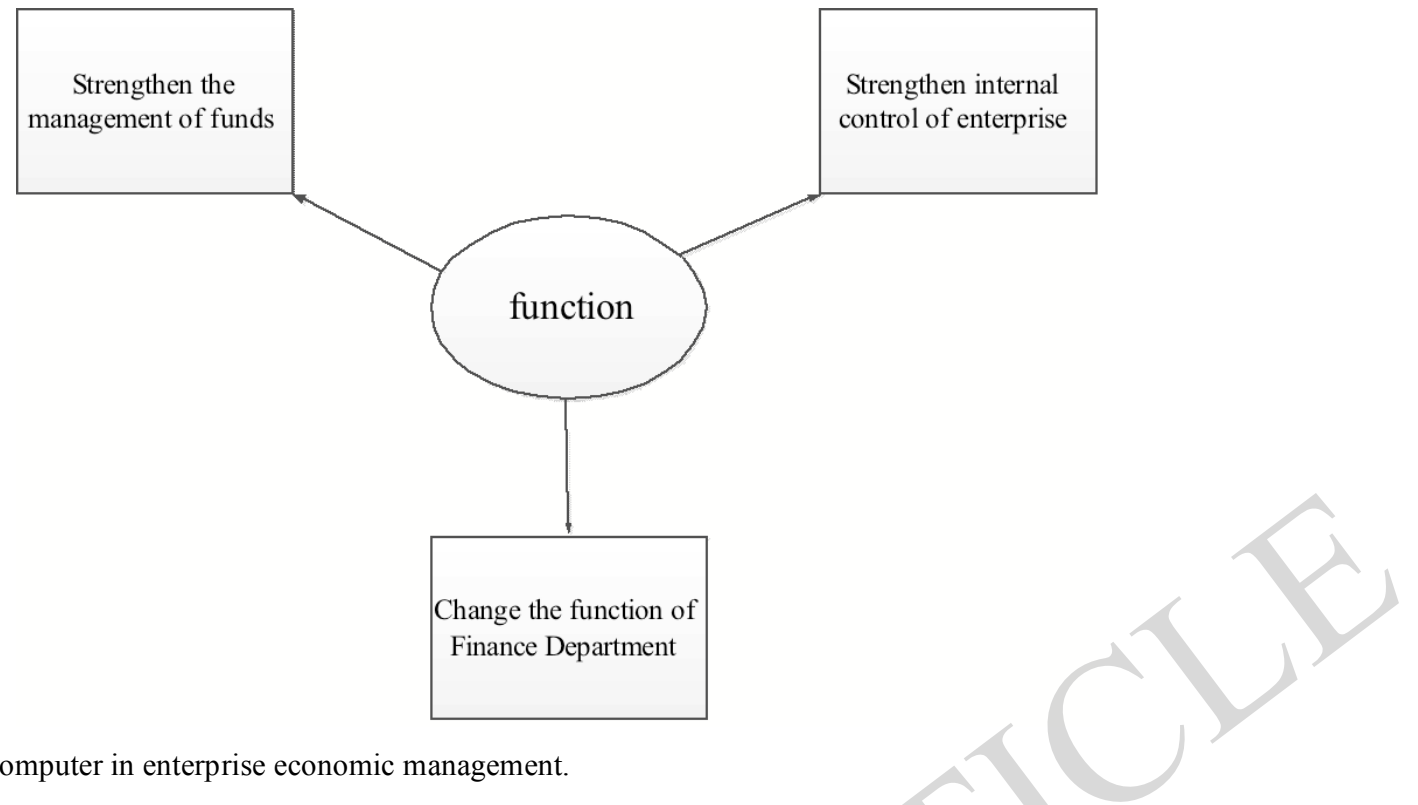

Fig. (3). The function of computer in enterprise economic management.

\subsection{Change the Function of the Finance Department}

The most important in the financial management is the management and processing of data, because the computer has greatly reduced the pressure of the original financial work.

\section{ATTENTION TO THE APPLICATION OF COM- PUTER TECHNOLOGY IN ENTERPRISE ECO- NOMIC MANAGEMENT}

The application of computer technology in the economic management of enterprises, which can not be achieved overnight, it requires enterprises have good development foundation, also need to continue to the application of technology for improvement and perfection, cope with the inevitable problems that all face, also make the management and employees truly recognize the importance of application of computer technology in enterprise's economic management, the only way to promote the application of computer technology.

The application of computer technology in enterprise's economic management is necessary to effectively solve the computer technology integration due to the change in the system of conflict management, deal with computer technology is the internal control system, the original business process and business practices behind the status quo and adopt positive and effective measures to solve. And in application management must follow the principle of order and effective, ensure that the computer technology in the economic management of standardization and standardization, management data code, management process of mass.

In order to promote the application of computer technology, enterprise managers in the management of increase the input of funds and equipment [15], according to the enterprise actual purchase appropriate management system and computer equipment, the establishment and implementation of computer network management information system, and hired or on the use of personnel to carry out specialized technical training, so as to meet the needs of modern enterprise management.
It is necessary to determine the central position of computer network system management. Because of the central position of computer network management, the real time update of enterprise management information is guaranteed. Management should establish websites dedicated to management information, the management work for enterprises to create a platform independent, with the computer as the platform for the exchange of information and management not media [16]. Through this platform can realize information resources sharing within the enterprise, in order to achieve enterprise information standardization and modernization, promote the enterprise personnel resource sharing and information communication.

The modern management of enterprise basically relies on the computer information processing to complete. The computer system includes the functional software of the aspects, such as communication, word processing, graphics and video software, etc. The establishment of computer information inside information protection system, through its own protection system, enterprise computer system is safe.

\section{CONCLUSION}

Thus, the computer in the enterprise economic management of the role is very huge, it brings the economic benefits of the enterprise which is also obvious. Along with the development of our market economy, the tremendous vitality of computer will show more and more obvious. While carrying out certain inputs will be the beginning of the modern management of the computer, but in the rate of recovery of funds, with the development of modern management and continuously accelerated, as is known to all, in modern enterprise management, focus on the management of business, the core business is the decision-making, decision is based on information. Information is investigated. In the enterprise management decision-making, the most important is the strategic decision-making, it is our entrepreneur managers one of the most important duties and center task. At present, the target system of the director's tenure is implemented in our country, which makes every enterprise pay more attention to 
and strengthen the formulation and use of strategic decisionmaking.

\section{CONFLICT OF INTEREST}

The authors confirm that this article content has no conflict of interest.

\section{ACKNOWLEDGEMENTS}

Declared none.

\section{REFERENCES}

[1] T.N. Isaeva, L.N. Safiullin, N.G. Bagautdinova, and R.N. Shaidullin "Aspects of a multi-level study of competitive performance of objects and subjects of economic management", World Applied Sciences Journal, vol. 27, no. 13, pp. 116-119, 2013.

[2] G. Belalem, S. Bouamama, and L. Sekhri, "An effective economic management of resources in cloud computing", Journal of Computers, vol. 6 , no. 3, pp. 404-411, 2011

[3] R.N. Lloret, "The management of e-book collections and their implication on the economic management of the library", The Bottom Line, vol. 24, no. 3, pp. 173-179, 2011.

[4] S. Dongwei, and X. Jiacai, "Liquidity, information content of stock prices and CEO incentives", Economic Research Journal, vol. 11, no. 005, pp. 56-70, 2013.

[5] R.J. Bessa, and M.A. Matos, "Economic and technical management of an aggregation agent for electric vehicles: a literature survey". European Transactions on Electrical Power, vol. 22, no. 3, pp. 334-350, 2012.
[6] R. Li, "Develop the foreign trade export brand to promote the enterprise economic management", China Foreign Trade (English version), vol. 12, p. 331, 2011

[7] J.I. Yun, Discussion about the way of chinese enterprise management that provides intellectual support to the transformation of the economic development pattern - a summary of "transformation of the economic development pattern and chinese enterprise management", Economic Management Journal, vol. 1, 2011.

[8] A.T. Peng, "The applied training model of enterprise management based on ERP simulating experience platform", Journal of Chemical \& Pharmaceutical Research, vol. 6, no. 6, p. 2303, 2014.

[9] O. Matsenko and D. Ovcharenko, "The quality of energy resources controlling as a part of effective enterprise management", Economic Annals-XXI, vol. 9, pp. 75-78, 2013.

[10] L.X. Cunningham and C. Rowley, "The changing face of small and medium-sized enterprise management in China", The Changing Face of Management in China, pp. 125-148, 2014.

[11] R.E. Hoyt and A.P. Liebenberg, "The value of enterprise risk management", Journal of Risk and Insurance, vol. 78, no. 4, pp. 795$822,2011$.

[12] M. Zaman, M.A. Butt, "Enterprise Management Information System: Design \& Architecture", International Journal of Computational Engineering Research (IJCER), vol. 2250, p. 3005, 2013.

[13] C. Fang, "Study on the application of ERP in enterprise management", Shandong Trade Unions' Tribune, vol. 4, p. 025, 2014.

[14] J. Erbes, H.R. Motahari-Nezhad and S. Graupner, "The future of enterprise IT in the cloud", Computer, vol. 5, pp. 66-72, 2012.

[15] J.A. Alalwan, H.R. Weistroffer, "Enterprise content management research: a comprehensive review", Journal of Enterprise Information Management, vol. 25, no. 5, pp. 441-461, 2012.

[16] H. Gongyou, H. Jiecheng and L. Li, "Design and implementation of enterprise management system based on the SaaS model and RFID”, Microcomputer Applications, vol. 4, p. 011, 2013.

Received: June 10, 2015

(C) Li and Xiong; Licensee Bentham Open.

This is an open access article licensed under the terms of the (https://creativecommons.org/licenses/by/4.0/legalcode), which permits unrestricted, noncommercial use, distribution and reproduction in any medium, provided the work is properly cited. 